\title{
Infantile Bartter syndrome with sensorineural deafness
}

INSERM

\section{Source}

INSERM. (1999). Orphanet: an online rare disease and orphan drug data base. Infantile Bartter syndrome with sensorineural deafness. ORPHA:89938

Infantile Bartter syndrome with deafness, a phenotypic variant of Bartter syndrome (see this term) is characterized by maternal polyhydramnios, premature delivery, polyuria and sensorineural deafness and is associated with hypokalemic alkalosis, increased levels of plasma renin and aldosterone, low blood pressure, and vascular resistance to ang iotensin II. 